www.jmscr.igmpublication.org

Impact Factor 5.84

Index Copernicus Value: 71.58

ISSN (e)-2347-176x ISSN (p) 2455-0450

crossref DOI:_https://dx.doi.org/10.18535/jmscr/v5i9.40

Journal Of Medical Science And Clinical Research

\title{
Flow cytometric analysis of CD 55 and CD 59 deficient cells in patients with Aplastic Anemia and their clinicohematological profile
}

\author{
Authors \\ Dr Ratnamala Choudhury, Dr Soumya Umesh, Dr Belsymol Cletus, \\ Dr Jananee Muralidharan, Dr Cecil Ross \\ Dept of Medicine, St. John's Medical College and Hospital, Bangalore \\ Corresponding Author \\ Dr Soumya Umesh \\ Phone number: 9008766555, Email: drsoumya239@gmail.com
}

\begin{abstract}
Background and Objectives: Acquired aplastic anemia $(A A)$ and paroxysmal nocturnal haemoglobinuria (PNH) are closely related diseases. The objective of our study was to determine the presence of this CD55 and CD 59 deficient clone in patients diagnosed with acquired idiopathic aplastic anemia and to record the clinicohaematological features, treatment and outcome of adults diagnosed with aplastic anemia at a tertiary care institution.
\end{abstract}

Methodology: All adults diagnosed with aplastic anemia presenting to a tertiary care center in Bangalore over a two-year time period were recruited and followed up. In these patients, the presence of CD55 and CD59 expression on erythrocytes was analyzed using flowcytometery. In addition, the clinicohaematological features; the treatment and response to therapy of these patients were recorded.

Results: Fifty-five patients diagnosed to have idiopathic aplastic anemia (AA) were followed up for a variable time period with a minimum duration of 3-month follow-up. In four of the patients (7.3\%), the presence of a small clone of CD55 and CD59 deficient population among erythrocytes was detected at diagnosis. Data from 24 patients who received cyclosporine for at least 3 months were analyzed.. At 3 months 7 out of 24 (29\%) showed partial response. At 1 year, out of 9 patients who followed up, 7 patients (77.7\%) were in partial remission (PR). Of three patients on androgen monotherapy, 2 patients (66\%) achieved partial remission after 12 weeks of monotherapy with danazol and one patient who followed up for 2 years continued to remain in partial remission. The overall response rate (ORR) noted in our study following ATG regime (ATG, cyclosporine, danazol and methylprednisolone) at the end of 6 months was $60 \%$.

Conclusion: Cyclosporine monotherapy was associated with lower response rates as compared to ATG combination therapy. Lower prevalence of CD55 and CD 59 deficient clone was perhaps due to the limitation that flowcytometric analysis was performed on erythrocytes alone.

Keywords: CD 55, CD 59, Aplastic anemia- paroxysmal nocturnal haemoglobinuria.

\section{INTRODUCTION}

Acquired aplastic anemia is a clinical syndrome in which there is fatty replacement of the marrow and a near absence of hematopoietic precursor cells. ${ }^{(1)}$ The specific medications administered for aplastic anemia depend on the choice of therapy, 
cost factors and whether it is supportive care only, immunosuppressive therapy or hematopoietic cell transplantation (HCT). Acquired aplastic anemia (AA) and paroxysmal nocturnal haemoglobinuria (PNH) are closely related diseases and $\mathrm{PNH}$ often occurs in patients with pre-existing aplastic anemia either concurrently or sequentially. The two diseases share similar clinical and pathologic features (i.e., pancytopenia and marrow hypocellularity). Clones of glycosylphosphatidylinositolanchor protein-deficient cells characteristically seen in PNH are present in about $40-50 \%$ of patients with severe aplastic anemia. ${ }^{(2)}$ Response to immunosuppressive therapy is better in this subset of patients and the bone marrow failure seen is less severe. ${ }^{(3,4)}$ Flow cytometry has allowed for sensitive and precise measurement of glycosylphosphatidylinositol-anchor protein-deficient red blood cells and neutrophils in severe aplastic anemia. The presence of an expanded PNH clone is associated with HLA-DR15 and has been reported as a good prognostic factor for the responsiveness to immunosuppressive therapy. In a cooperative study from France of 220 patients with PNH (defined by a positive Ham test), there was a previous history of AA in $30 \%$, and for the remainder, the actuarial risk of developing pancytopenia was estimated at $14 \%$ at 4 years. ${ }^{(5)}$ Conversely, AA can evolve into PNH months or years after successful immunosuppressive treatment; many patients have only a positive Ham test or a population of granulocytes lacking glycophosphoinositol-linked proteins. In one study, a presumptive diagnosis of PNH based on flow cytometry was made in almost $50 \%$ of AA cases at presentation. ${ }^{(6)}$ Longitudinal studies of patients with de novo PNH or PNH developing from AA indicate a low probability of spontaneous remission, and in many patients, the contribution of the PNH clones remains stable for years. As there is a dearth of studies in this subgroup of patients in India, this study was undertaken.

\section{MATERIALS AND METHODS}

This was a prospective observational study conducted at a tertiary care center over a two-year time period and recruited all consenting patients who presented with idiopathic aplastic anemia. Patients with aplastic anemia secondary to drugs, infections, connective tissue disease etc were excluded from the study. A total of fifty-five patients met the inclusion criteria and were followed up for a minimum period of three months.

Aplastic anemia was diagnosed based on bone marrow study and hematological parameters. The patients were classified into severe AA, very severe AA and non-severe AA based on validated predefined criteria as described below. ${ }^{(7,8)}$

\begin{tabular}{|c|c|c|c|c|c|}
\hline $\begin{array}{l}\text { Diagnostic } \\
\text { Categories }\end{array}$ & $\mathbf{H b}$ & $\begin{array}{l}\text { Reticulocyte } \\
\text { Concentration }\end{array}$ & $\begin{array}{l}\text { Neutrophil } \\
\text { Count }\end{array}$ & $\begin{array}{l}\text { Platelet } \\
\text { Count }\end{array}$ & $\begin{array}{l}\text { Marrow } \\
\text { Biopsy }\end{array}$ \\
\hline $\begin{array}{c}\text { Moderately } \\
\text { severe }\end{array}$ & $<100 \mathrm{~g} / \mathrm{L}$ & $<40 \times 10^{9} / \mathrm{L}$ & $\begin{array}{c}<1.5 \times \\
10^{9} / \mathrm{L}\end{array}$ & $\begin{array}{c}<50 \quad x \\
10^{9} / \mathrm{L}\end{array}$ & $\begin{array}{l}\text { Marked } \\
\text { decrease of } \\
\text { hematopoietic } \\
\text { cells. }\end{array}$ \\
\hline Severe & $<90 \mathrm{~g} / \mathrm{L}$ & $<30 \times 10^{9} / \mathrm{L}$ & $\begin{array}{c}<0.5 \times \\
10^{9} / \mathrm{L}\end{array}$ & $\begin{array}{c}<30.0 \times \\
10^{9} / \mathrm{L}\end{array}$ & $\begin{array}{l}\text { Marked } \\
\text { decrease or } \\
\text { absence of } \\
\text { hematopoietic } \\
\text { cells. }\end{array}$ \\
\hline $\begin{array}{l}\text { Very } \\
\text { Severe }\end{array}$ & $<80 \mathrm{~g} / \mathrm{L}$ & $<20 \times 10^{9} / \mathrm{L}$ & $\begin{array}{c}<0.2 \times \\
10^{9} / \mathrm{L}\end{array}$ & $\begin{array}{c}<20.0 \times \\
10^{9} / \mathrm{L}\end{array}$ & $\begin{array}{l}\text { Marked } \\
\text { decrease or } \\
\text { absence of } \\
\text { hematopoietic } \\
\text { cells. }\end{array}$ \\
\hline
\end{tabular}

Figure 1 : Classification of Aplastic Anemia 
At diagnosis, CD55 + CD59 expression on erythrocytes were analyzed using multicolour (four colour) BDFACS Caliburflowcytometer. Flow cytometric analysis in addition to identifying a population of GPI-AP-deficient cells, can both determine the percentage of cells that are abnormal and identify discrete populations with different degrees of deficiency. Erythrocytes with

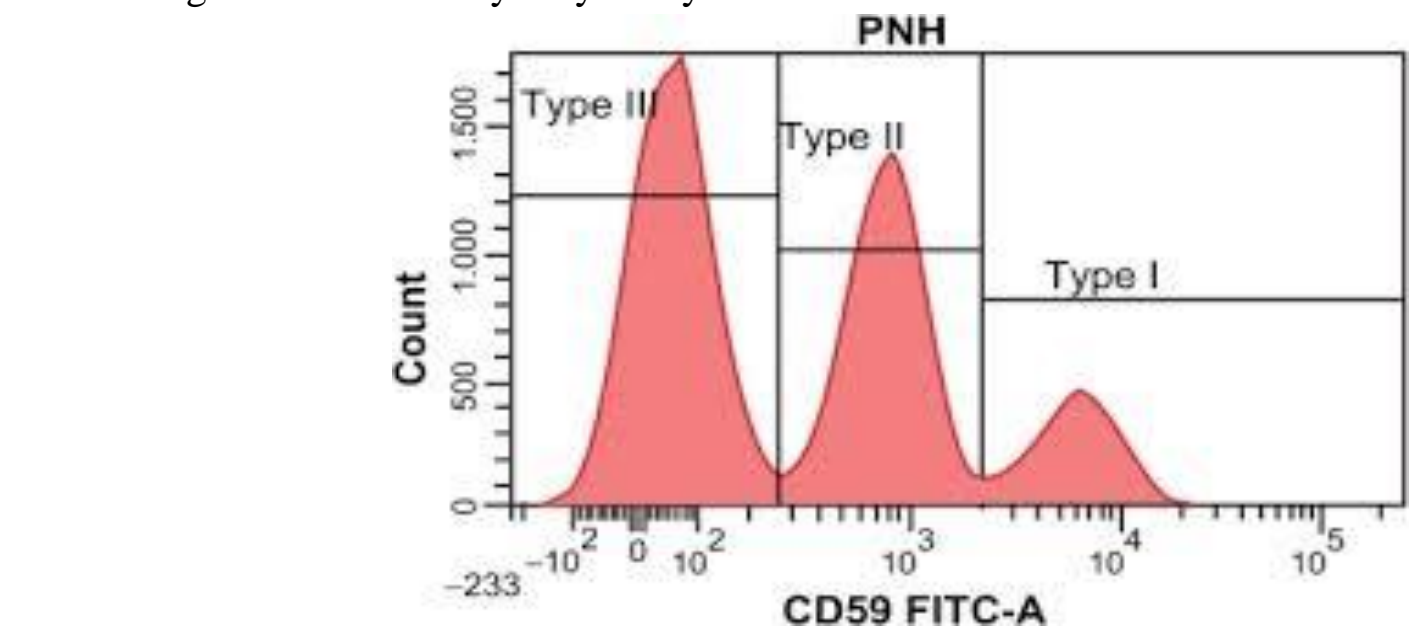

complete deficiency of GPI-APs are called PNH III, those with subtotal deficiency (usually $\leq 10 \%$ of normal expression) are called PNH II, and those with normal expression are called PNH I (Figure 1). Knowing both the percentage and type of deficient red cells is helpful in managing the anemia of PNH.

Figure 2 : Patients with high percentage of Type III cells have higher chance of hemolysis than patients with lower percentage of Type III cells.

At each follow-up visit, complete blood count and transfusion requirements were noted,to assess response to treatment based on the most recent consensus guidelines published in the British Journal of Hematology in 2012 and is described below.

\begin{tabular}{|c|c|c|}
\hline Response & SAA & Non SAA \\
\hline - None & - Still severe & - Worse or not meeting criteria below \\
\hline - Partial & $\begin{array}{l}\text { Transfusion } \\
\text { independent } \\
\text { - No longer meeting } \\
\text { criteria }\end{array}$ & $\begin{array}{l}\text { Transfusion independent(if previously } \\
\text { dependent) } \\
\text { or doubling or normalisation of atleast one } \\
\text { cell line } \\
\text { or increase in baseline } \mathrm{Hb}>3 \mathrm{~g} / \mathrm{dL} \text { (if } \\
\text { initially }<6 \mathrm{~g} / \mathrm{dL} \text { ) } \\
\text { or neutrophils }>500 / \mu \mathrm{L}(\text { if initially }<500 \text { ) } \\
\text { or platelets }>20,000 / \mu \mathrm{L} \text { (if initially } \\
<20,000)\end{array}$ \\
\hline - Complete & $\begin{array}{ll}\text { - } & \text { Hb: normal } \\
\text { - } & \text { Neutrophils }>1500 / \mu \mathrm{L} \\
\text { - } & \text { Platelets }>1.5 \text { lacs } / \mu \mathrm{L}\end{array}$ & - Same as for SAA \\
\hline
\end{tabular}

Figure 3: Assessment of response to treatment in Non-severe Aplastic anemia (Non SAA) and Severe Aplastic anemia (SAA)

\section{Statistical Analysis}

Descriptive statistical analyses (rates, proportions, and medians) were carried out using the SPSS version 16.0 software package.

\section{RESULTS}

Among the 55 patients included in our study, 32 were males (M:F ratio: 1.4:1). The mean age in our study was $39.8 \pm 16.1$ years with a bimodal 


\section{JMSCR Vol||05||Issue||09||Page 27604-27611||September}

peak at the age group of 20-30 years and again at 50-60 years of age. Of all the patients, majority i.e. 31 patients $(56.5 \%)$ presented with symptoms of anemia. Sixteen patients $(30 \%)$ presented with bleeding manifestations and 8 patients $(14.5 \%)$ presented with neutropenic sepsis /fever as the initial presentation.
All patients were followed up for a minimum duration of 3 months. Twenty-two patients were followed up for a duration of two years. Out of the 55 patients, presence of a small clone of CD55 and CD 59 deficient population was detected in 4 of the patients $(7.3 \%)$ at diagnosis.

The patients were divided into nonsevere, severe and very severe AA as described below.

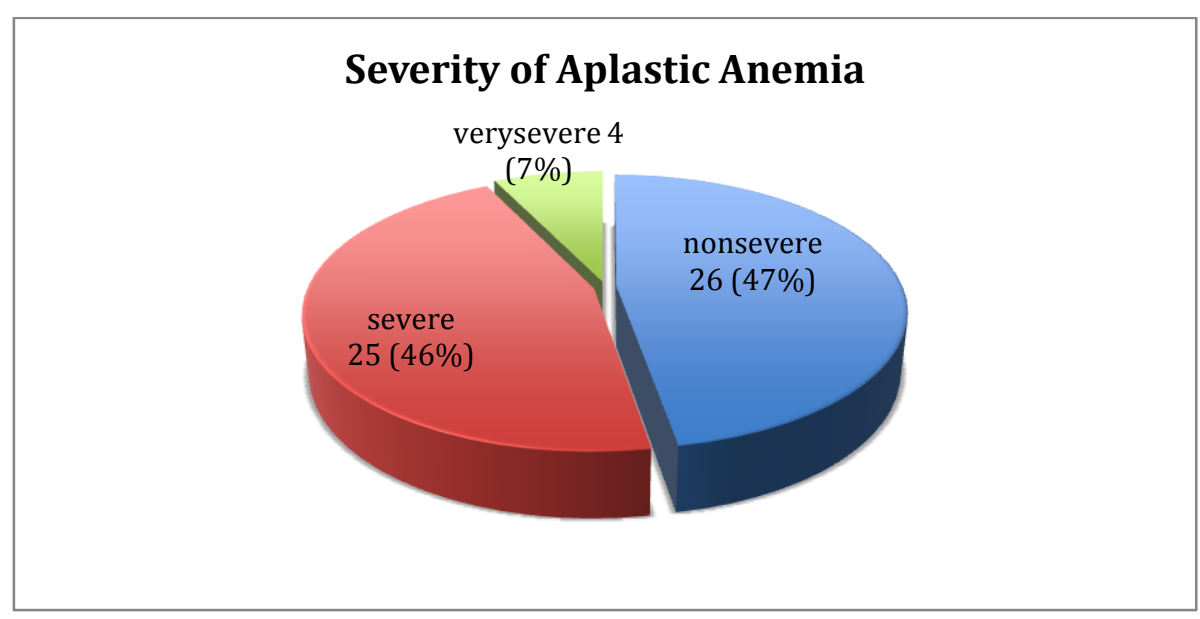

Figure 4: Classification of Aplastic anemia in study population

Our patients were put on the following four treatment modalities (ATG- antithymocyte globulin, combination immunosuppresive treatment, androgens, and cyclosporin only) based on the severity categories and cost factors.
Combination immunosuppresive therapy (IST) consisted of Cyclosporin with androgen. Three patients were managed only with blood transfusions as shown in figure 5. The patients were then followed up and assessed for response.

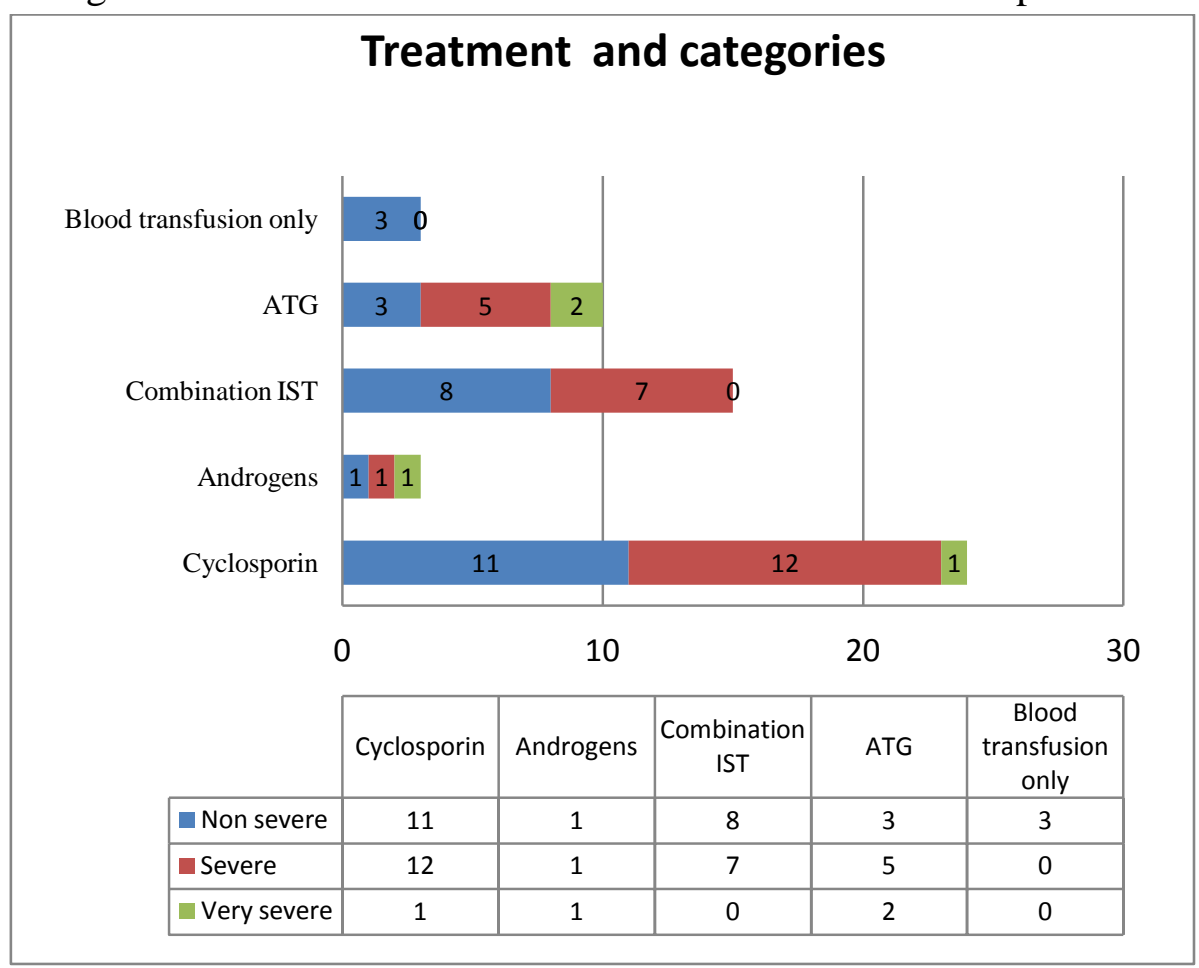

Figure 5: Treatment categories based on severity 


\section{Cyclosporine monotherapy}

Data from 24 patients who received cyclosporine were analyzed. At 3 months 7 out of 24 (29\%) showed partial response. At 6 months, out of 13 patients who followed up, no one achieved complete remission (CR), 9 patients achieved partial remission (PR) and 4 patients continued to remain in no remission. At 1 year, out of 9 patients who followed up, 7 patients were in partial remission (PR) and 2 patients were non responders. Complete remission was not noted in anyone when followed up for one year and also among the 7 patients who continued to follow up to 2 years on cyclosporine monotherapy. Hence in our study cyclosporine monotherapy was not associated with a complete response despite the duration of treatment.

\section{Androgen monotherapy}

Only three patients were on androgen monotherapy of which only one patient was followed up for the full duration of 2 years and remained in partial remission. Two patients $(66 \%)$ achieved partial remission after 12 weeks of monotherapy with danazol.

\section{ATG regime}

With the exception of one patient, the timing of initiation of ATG was after the first three months of diagnosis. Ten patients (18\%) were treated with ATG regime once during the 2 year follow up period. ATG regime was initiated at varying points of time during the 24 month follow up period. Among the 10 patients treated, the overall response at 6 months following ATG was $60 \%$.Three patients showed complete response, and two patients were followed up to 3 months post ATG and had achieved partial response by then. Two patients were lost to follow-up. One patient remaineda non-responder, and one patient relapsed after showing initial response. One patient developed neutropenic sepsis and died on treatment.
One patient underwent allogenic bone marrow transplant after 3 months of diagnosis and is currently on follow up.

\section{Combination IST}

Of the fifteen patients, who received combination immunosuppressive treatment with cyclosporine and androgen, 2 patients showed partial response at the end of 3 months while rest showed no response. Only six patients followed up for two years, of which only one patient showed complete response and three other patients showed partial response and two patients were non-responders. Of the 4 patients who were diagnosed as AA-PNH due to the presence of the clone, 3 were in the category of severe AA of which one patient succumbed to the illness after 3 months of diagnosis and other two patients had partial response at the end of three months. One patient was in the category of non-severe aplastic anemia and was followed up to $2 \mathrm{yrs}$ and had partial response. Among these four patients with the PNH clone, none received ATG. They were treated either with cyclosporine or androgens. However the numbers were small to comment on whether the presence of the clone had any influence on outcome with immunosuppressive therapy.

\section{Long term outcome}

Out of the 55 patients, 23 patients remained in follow up at the end of two years. The outcome in these patients is depicted below. 


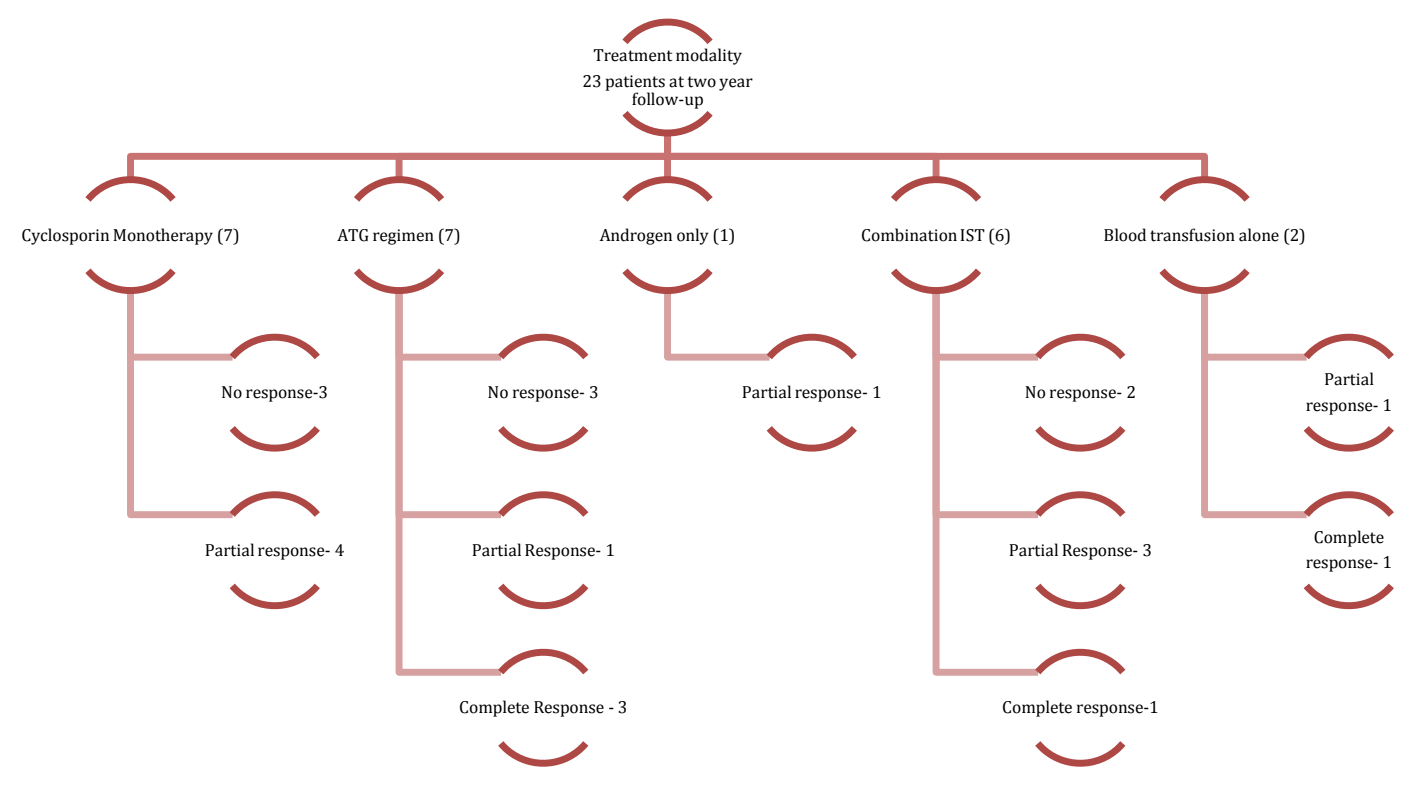

Figure 6: Response at the end of 2 year follow-up

\section{DISCUSSION}

In our study, the diagnosis of Idiopathic aplastic anemia (AA) was based on blood indices and trephine bone biopsy. The patients were further sub-categorized into non severe, severe (SAA) and very severe aplastic anemia (VSAA). Fiftyfive patients with AA, who attended the Medicine/Hematology OPD or admitted in the medical wards of St John's Medical College Hospital, were included in the study. As per our hospital based statistics, the occurrence of aplastic anemia was 39 patients per 1 lakh population. The mean age of our patients was $39.8 \pm 16.1$ years with a male: female ratio of $1.4: 1$. There was a bimodal peak noted in the age groups, which was also seen in a study by Heimpel et al and Szklo et al. $^{(9,10)}$

The most common presenting symptom was due to anemia in our patients. Mohler et al in their series of 50 patients have also described symptoms of anemia as the commonest presenting symptom, findings similar to our study. ${ }^{(11)}$

CD55 and CD 59 by flow cytometry, is a sensitive and quantitative test for PNH enabling the detection of small PNH clones which occur in up to $50 \%$ of patients with aplastic anemia, the proportion depending on the sensitivity of the flow cytometric analysis used. ${ }^{(12)}$ Out of the 55 patients, presence of a small clone of CD55 and
CD 59 was detected in $7.3 \%$ of our patients at diagnosis. This disparity can be accounted for the fact that the flowcytometric analysis initially performed at our institution was on RBC's alone. Hence we may have underestimated the prevalence of the clone. Currently the flowcyometer in our hospital can analyse the granulocyte lineage also. Due to the small number, we were unable to draw meaningful conclusions on the effect of the presence of the clone in patients with aplastic anemia.

\section{Treatment}

\section{Cyclosporine monotherapy}

Twenty-four of our AA patients were on cyclosporine monotherapy, of whom only seven patients (29\%) showed partial response at the end of 3 months. This is not in concordance with a sponsored study performed at Chandigarh by Varma et al which showed $30.8 \%$ full response and $15.8 \%$ had partial response at 12 weeks of monotherapy. ${ }^{(13)}$

According to a study done in Yemen at the 6month evaluation $2(14.3 \%)$ patients had complete response and $5(35.7 \%)$ patients had partial response. ${ }^{(14)}$ In our study at 6 months, $69.2 \%$ of the patients had partial response. No patient showed complete response following monotherapy with cyclosporine at any point in our study. 


\section{Androgen monotherapy}

In a study by Chuhjo et al, sixteen patients on androgen monotherapy who completed the 12week treatment period, 5 (31.3\%) showed a partial response. ${ }^{(15}$ In our study, only three patients were on androgen monotherapy of which only one patient was followed up for the full duration of 2 years and remained in partial remission. Two patients $(66 \%)$ achieved partial remission after 12 weeks of monotherapy with danazol.

\section{ATG regime}

Of the 10 patients, the overall response at 6 months following ATG was $60 \%$.Of the three patients who achieved $\mathrm{CR}$ at the end of three years, one belonged to the category of NSAA, SAA and VSAA each respectively. Overall response at 6 months after initiation of treatment was $85.8 \%$ as per a study by Nair et al in Pune. ${ }^{(16)}$ In another similar study done by Malhotra et al the overall response rate was $58 \%$ at 3 months, and $77 \%$ at 6 months. ${ }^{(17)}$

\section{Combination IST}

Of the fifteen patients, who received combination immunosuppressive treatment with cyclosporine and androgen, only 2 patients showed partial response at the end of 3 months. At 2 years, six patients remained in follow-up. In this subset, one patient showed complete response and 3 other patients showed partial response. The overall response rate for this combination IST in a large scale study of 1501 patients with aplastic anemia in a tertiary care center was found to be $45.6 \%{ }^{(18)}$

\section{CONCLUSION}

In our study of patients with aplastic anemia presenting to our tertiary care centre over a two year time period, we noted the following demographic patterns. A bimodal distribution was noted in the age group of patients with a peak in 20-30 years of age and again at 50-60 years of age. There was a male:female ratio of $1.4: 1$ in our patients. The most common presentation was with symptoms of anemia. Fever as the presenting complaint was less common.

Cyclosporine monotherapy or in combination with androgens /ATG formed the major bulk of our treatment regimen. Cyclosporine monotherapy did not show complete response in our follow up studies. Cyclosporine in combination with androgens (Combination IST) has shown better response with four out of six patients at the end of two year follow-up showing response. Cyclosporine with ATG showed an overall response rate of $60 \%$ in our hospital at 6 months follow up. Bone marrow transplantation was less common at our center due to lack of matched donors and financial constraints.

In only four $(7.3 \%)$ of patients, we noted the presence of a small clone of CD55 and CD 59 deficient population among erythrocytes. The numbers were not sufficient to analyse. To obtain accurate information about the percentage of GPIAP-deficient erythrocytes, analysis should be performed prior to transfusion or during a period of transfusion abstinence (at least 1 month, but longer if clinically safe). Also, analysis of expression of GPI-AP on granulocytes provides additional clinically relevant information as granulocytes more accurately reflect the $\mathrm{PNH}$ clone size and remains unaffected by red cell transfusion. In our study, many of the patients had received blood transfusions outside and analysis for the clone was done only on erythrocytes. This remains a limitation of our study. The number of patients in both groups (with and without clone) being non-comparable, their difference in treatment outcome could not also be studied. Hence, larger studies involving multiple centers and longer study duration are neededin the future.

\section{REFERENCE}

1. Lichtman, George B, Marshall A. Williams Hematology, Chapter 34. Aplastic Anemia: Acquired and Inherited. 8th ed. Josef T, Thomas J, Uri S, Kenneth K, Marshall A, editors.: McGraw Hill; 2010 
2. Young N. Paroxysmal nocturnal hemoglobinuria and myelodysplastic syndromes: clonal expansion of PIG-A-mutant hematopoietic cells in bone marrow failure. Haematologica. 2009; 94(1): p. 3-7.

3. Ishiyama K, Chuhjo T, Wang H, Yachie A, Omine M. Polyclonal hematopoiesis maintained in patients with bone marrow failure harboring a minor population of paroxysmal nocturnal hemoglobinuriatype cells. Blood. 2003; 102: p. 12111216.6

4. Maciejewski J, Rivera C, Kook H, Dunn D, Young N. Relationship between bone marrow failure syndromes and the presence of glycophosphatidyl inositolanchored protein-deficient clones. $\mathrm{Br} \mathrm{J}$ Haematol. 2001; 115: p. 1015-1022.

5. Socie G, Mary JY, Gramont A, Rio B. Paroxysmal nocturnal haemoglobinuria: Long-term follow-up and prognostic factors. Lancet. 1996; 348: p. 573.

6. Schrenzenmeier H, Hertenstein B, Wagner B. A pathogenetic link between aplastic anemia and paroxysmal nocturnal hemoglobinuria is suggested by a high frequency of aplastic anemia with a deficiency of phosphatidylinositol glycan proteins. Exp Hematol. 1995; 23: p. 81.

7. Camitta BM, Thomas ED, Nathan DG, Santos G, Gordon-Smith EC, Gale RP,Rappeport JM, Storb R. Severe aplastic anemia: a prospective study of the effect of early marrow transplantation on acute mortality. Blood. 1976 Jul;48(1):63-70.

8. Bacigalupo A. Bone marrow transplantation for severe aplastic anemia from HLA identical siblings. Haematologica. 1999;84(1):2-4.

9. Heimpel H. Epidemiology and aetiology of aplastic Anemia. In Bacigalupo HS\&A, editor. Aplastic Anemia: Pathophysiology and Treatment. U.K.: Cambridge University Press; 2000. p. 97-116.
10. Szklo M, Sensenbrenner L, Markowitz J, Weida S. Incidence of aplastic anemia in metropolitan Baltimore: a populationbased study. Blood. 1985 Jul; 66(1): p. 115-9.

11. Mohler N, Leavell S. Aplastic Anemia : An analysis of 50 cases. Ann Int Med. 1958; 49:2: p. 326.

12. Dunn DE,Ware RE, Parker CJ, et al. Research directions in paroxysmal nocturnal hemoglobinuria.Immunol Today. 1999;20:168-171.

13. Varma S, Varma N, Malhotra P, Singh S, Sharma DR. Cyclosporin A monotherapy in young Indian aplastic anaemia patients. J Indian Med Assoc. 1999 Dec;97(12): 505-6. PubMed PMID: 10638130.

14. Jameel, Waled, Jahafi A. Cyclosporine monotherapy for severe aplastic anemia:A developing country experience. Ann Saudi Med. 2005 Sept; 25.1

15. Chuhjo T, Yamazaki H, Omine M, Nakao S. Danazol therapy for aplastic anemia refractory to immunosuppressive therapy. Am J Hematol. 2008 May; 83: p. 387-9.

16. Nair V, Sharma A, Das S, Sondhi V, Sharma S. Immunosuppressive therapy in adults with aplastic Anemia: singleinstitution experience from India. Postgrad Med J. 2013 Sep; 89(1055): p. 508-15.

17. Malhotra P, Bodh V, GuruMurthy G, Datta A. outcomes of immunosuppressant therapy with lower dose of antithymocyte globulin and cyclosporine in aplastic anemia. Hematology. 2014 Sep: p. 2.

18. Mahapatra M, Singh PK, Agarwal M, Prabhu M, Mishra P, Seth T, Tyagi S, Patil HP, Saxena R. Epidemiology, ClinicoHaematological Profile and Management of Aplastic Anaemia: AIIMS Experience. J Assoc Physicians India. 2015 Mar;63 (3Suppl):30-5. PubMed PMID: 26529865. 